\title{
Indications for Thyroid FNA and Pre-FNA Requirements: A Synopsis of the National Cancer Institute Thyroid Fine-Needle Aspiration State of the Science Conference
}

Edmund S. Cibas, M.D. ${ }^{1,2 *}$ Erik K. Alexander, M.D., ${ }^{3,4}$ Carol B. Benson, M.D., ${ }^{5,6}$ Pedro Patricio de Agustín, M.D., Ph.D., ${ }^{7}$ Gerard M. Doherty, M.D., ${ }^{8,9}$ William C. Faquin, M.D., Ph.D., William D. Middleton, M.D., F.A.R.C., ${ }^{11}$ Theodore Miller, M.D., ${ }^{12}$ Stephen S. Raab, M.D., ${ }^{13}$ Matthew L. White, M.D., ${ }^{8,9}$ and Susan J. Mandel, M.D., M.P.H. ${ }^{14}$

The National Cancer Institute (NCI) sponsored the NCI Thyroid Fine-Needle Aspiration (FNA) State of the Science Conference on October 22-23, 2007 in Bethesda, MD. The 2-day meeting was accompanied by a permanent informational website and several on-line discussions between May 1 and December 15, 2007 (http://thyroidfna.cancer.gov). This document summarizes the indications for performing an FNA of a nodule discovered by physical examination or an imaging study; the indications for using ultrasound versus palpation for guidance when performing a thyroid FNA; the issues surrounding informed consent for thyroid FNA; and the information required on a requisition form that accompanies a thyroid
FNA specimen. (http://thyroidfna.cancer.gov/pages/info/agenda/) Diagn. Cytopathol. 2008;36:390-399. @ 2008 Wiley-Liss, Inc. ${ }^{\dagger}$

Key Words: thyroid; cytology; fine-needle aspiration; indications; consent form

The authors of this document comprised Committee I of the NCI Thyroid Fine-Needle Aspiration (FNA) State of the Science Conference. The charge of this committee was to evaluate the state of the science of thyroid FNA with regard to the indications for performing a thyroid
${ }^{1}$ Department of Pathology, Brigham and Women's Hospital, Boston, Massachusetts

${ }^{2}$ Department of Pathology, Harvard Medical School, Boston, Massachusetts

${ }^{3}$ Department of Medicine, Brigham and Women's Hospital, Boston, Massachusetts

${ }^{4}$ Department of Medicine, Harvard Medical School, Boston, Massachusetts

${ }^{5}$ Department of Radiology, Brigham and Women's Hospital, Boston, Massachusetts

${ }^{6}$ Department of Radiology, Harvard Medical School, Boston, Massachusetts

${ }^{7}$ Department of Pathology, University Hospital "12 de Octubre”, Madrid, Spain

${ }^{8}$ Department of Surgery, St. Joseph Mercy Hospital, Ann Arbor, Michigan

${ }^{9}$ Department of Surgery, University of Michigan, Ann Arbor, Michigan

${ }^{10}$ Department of Pathology, Massachusetts General Hospital, Boston, Massachusetts

${ }^{11}$ Mallinckrodt Institute of Radiology, Washington University School of Medicine, St. Louis, Missouri

${ }^{12}$ Department of Pathology, University of California San Francisco, San Francisco, California
${ }^{13}$ Department of Pathology, University of Colorado at Denver, Aurora, Colorado

${ }^{14}$ Department of Medicine, University of Pennsylvania, Philadelphia, Pennsylvania

The following medical societies are co-sponsors of the NCI Thyroid Fine-Needle Aspiration State of the Science Conference and Website: The American Cancer Society; College of American Pathologists; The American Society for Clinical Pathology; The American Society of Clinical Oncology; La Societe Francaise de Cytologie Clinique; The American Society of Cytopathology; The Papanicolaou Society of Cytopathology; The American Association of Clinical Endocrinologists; The American Association of Endocrine Surgeons; The American Thyroid Association; The Society of Radiologists in Ultrasound; The American College of Radiology; National Comprehensive Cancer Network; and The American College of Endocrinology.

*Correspondence to: Edmund S. Cibas, M.D., Department of Pathology, Brigham and Women's Hospital, 75 Francis St., Boston, MA 02115. E-mail: ecibas@partners.org

Received 27 February 2008; Accepted 27 February 2008

DOI 10.1002/dc.20827

Published online in Wiley InterScience (www.interscience.wiley.com). 
FNA and the prethyroid FNA requirements. This is a summary of the "Review and Conclusions" of the subject matter that this committee analyzed based on literature reviews limited to English language publications dating back to 1995 using PubMed as the search engine, with key words determined by the committee members; online forum discussions (http://thyroidfna.cancer.gov/forums/ default.aspx); and formal interdisciplinary discussions held at the October 2007 conference. This is not a "standards of practice" guideline, nor is it endorsed as such by the National Cancer Institute.

\section{Indications for Performing an FNA of a Thyroid Nodule Discovered by Palpation}

Every patient with a palpable thyroid nodule is a candidate for fine-needle aspiration (FNA) and should undergo further evaluation to determine if an FNA is warranted. ${ }^{1-3}$ Thyroid nodules detected by palpation are usually at least $1.0 \mathrm{~cm}$ in dimension ${ }^{4,5}$ and are therefore potentially clinically significant. Before a decision is made to perform an FNA, a complete history should be obtained; a physical examination directed to the thyroid gland and cervical lymph nodes should be performed; and a serum thyrotropin level (TSH) and thyroid ultrasound (US) should be obtained. ${ }^{1,3,6-8}$

Significant history or physical examination findings that increase the likelihood of malignancy include a family history of thyroid cancer, prior head and neck or total body irradiation, rapid growth of the nodule, a very firm or hard nodule, hoarseness or vocal cord paralysis, ipsilateral cervical lymphadenopathy, and fixation of the nodule to surrounding tissues. $1,3,6,9,10$

Patients with a normal or elevated serum TSH level should proceed to a thyroid US to determine if an FNA needs to be performed (see section "Indications for Performing an FNA of a Thyroid Nodule Discovered via Imaging"); those with a depressed serum TSH should have a radionuclide thyroid scan, the results of which should be correlated with the sonographic findings. $1,3,6,7,11$ Functioning thyroid nodules in the absence of significant clinical findings do not require an FNA because the incidence of malignancy is exceedingly low. ${ }^{12}$ A nodule that appears either iso- or hypo-functioning on radionuclide scan should be considered for FNA based on the US findings (see section "Indications for Performing an FNA of a Thyroid Nodule Discovered via Imaging"). ${ }^{1-3}$

Contraindications to thyroid FNA are very few: an uncooperative patient and a severe bleeding diathesis. In such circumstances appropriate medical consultation should be sought prior to the FNA. ${ }^{13-15}$ The most significant (but extremely rare) complication of thyroid FNA, limited to a few case reports and small series, is intrathyroidal hemorrhage and acute upper airway obstruction. ${ }^{16}$
Extrapolating from recommendations for endoscopic USguided FNA, it is usually possible to perform an FNA on a patient who is taking standard doses of aspirin, other nonsteroidal anti-inflammatory drugs (NSAIDS), or prophylactic low molecular weight heparins (LMWH). ${ }^{3,14,17,18}$ Nevertheless, consideration should be given to stopping LMWH at least 8 hour before the procedure. ${ }^{19}$ In patients taking therapeutic doses of warfarin or heparin/LMWH, performing a thyroid FNA is controversial but can be done. ${ }^{18,19}$ There are no data on the safety of FNA in patients taking anti-platelet medications like Plavix ${ }^{\circledR}$ (clopidogrel bisulfate). A reasonable approach is to stop the medication for 3-5 days with agreement from the prescribing doctor. If this cannot be done safely, an FNA may be performed using the smallest needle possible and limiting the number of passes performed. In this scenario, US guidance may be preferable so that the surrounding small vessels can be visualized and avoided.

Conclusions:

1. Before biopsying a patient with one or more thyroid nodules discovered by palpation, a serum TSH level should be measured and an US examination performed.

2. If the serum TSH level is depressed, the findings of a radionuclide thyroid scan should be correlated with those of US examination. If the nodule of interest is hot, an FNA is not indicated.

3. If the serum TSH is normal or elevated, an US examination should be performed to determine if sonographic criteria for FNA are met (see section "Indications for Performing an FNA of a Thyroid Nodule Discovered via Imaging"). If so, the nodule should be biopsied.

4. An FNA may be contraindicated if the patient is uncooperative.

5. An FNA may be contraindicated if the patient has a severe bleeding diathesis.

\section{Indications for Performing an FNA of a Thyroid Nodule Discovered via Imaging}

A nodule not previously suspected or discovered clinically but detected by an imaging study is considered an incidental nodule ("incidentaloma"). Whether or not a nodule has been detected clinically depends on the expertise of the person performing the clinical examination (if one was done), the size and mobility of the patient's neck, and the size and location of the nodule.

Incidentalomas detected by ${ }^{18}$ FDG-PET are unusual (2-3\% of all PET scans) but have a higher risk of cancer (14-50\%) compared to the background incidence. ${ }^{20-28} \mathrm{~A}$ focal ${ }^{18}$ FDG-PET-avid thyroid nodule is much more likely to be a primary thyroid cancer than metastatic disease to the thyroid, even in patients with an extrathyroidal 
CIBAS ET AL.

Table I. Indications for Thyroid FNA: Recommendations of Professional Societies

\begin{tabular}{|c|c|c|c|}
\hline$A C T^{\mathrm{a}}$ & $A T A^{\mathrm{b}}$ & $A A C E^{\mathrm{a}}$ & $S R U^{\mathrm{b}}$ \\
\hline$<10 \mathrm{~mm}$ & $<10 \mathrm{~mm}$ & $<10 \mathrm{~mm}$ & $<10 \mathrm{~mm}$ \\
\hline FNA if clinical risk factors & $\begin{array}{l}\text { FNA if clinical risk factors or } \\
\text { suspicious US features }\end{array}$ & $\begin{array}{l}\text { FNA if clinical risk factors or } \\
\text { suspicious US features }\end{array}$ & No recommendation \\
\hline $5-10 \mathrm{~mm}$ & & & $>10 \mathrm{~mm}$ \\
\hline $\begin{array}{l}\text { FNA if suspicious US features } \\
10-20 \mathrm{~mm}\end{array}$ & & & $\begin{array}{l}\text { FNA if microcalcifications } \\
>15 \mathrm{~mm}\end{array}$ \\
\hline FNA most nodules & & & FNA if solid with coarse calcifications \\
\hline \multicolumn{4}{|l|}{$\begin{array}{l}\text { May defer FNA if benign US } \\
\text { features }\end{array}$} \\
\hline$>20 \mathrm{~mm}$ & $>10-15 \mathrm{~mm}$ & $>10 \mathrm{~mm}$ & $>20 \mathrm{~mm}$ \\
\hline FNA all & FNA all & FNA all & $\begin{array}{l}\text { FNA if mixed solid \& cystic or cystic } \\
\text { with mural nodule }\end{array}$ \\
\hline
\end{tabular}

ACT, Academy of Clinical Thyroidologists; ATA, American Thyroid Association; AACE, American Association of Clinical Endocrinologists; SRU, Society of Radiologists in Ultrasound. . $^{38}$

${ }^{\mathrm{a}}$ Nodule size not specified as maximum or mean.

${ }^{\mathrm{b}}$ Nodule size refers to maximum dimension.

malignancy. Many ${ }^{18}$ FDG-PET-avid lesions that are not papillary cancer are follicular or Hurthle cell neoplasms. Therefore, a focal nodule that is ${ }^{18}$ FDG-PET-avid is an indication for FNA. This applies only to focal lesions. Diffuse increased uptake on ${ }^{18}$ FDG-PET does not warrant FNA unless thyroid sonography detects a discrete nodule.

All focal hot nodules detected on sestamibi scans and confirmed by US to be a discrete nodule should undergo FNA. Thyroid incidentalomas detected on sestamibi scans have a high risk of cancer (22-66\%). ${ }^{29-33}$ Many that are not papillary cancer are follicular neoplasms.

Incidentalomas detected by US (such as carotid Doppler scans or scans done for parathyroid disease) have a cancer risk of $\sim 10-15 \%(0-29 \%)^{34-46}$ and should undergo dedicated thyroid sonographic evaluation. Lesions with a maximum diameter greater than 1.0-1.5 $\mathrm{cm}$ should be considered for biopsy unless they are simple cysts or septated cysts with no solid elements. FNA may also occasionally be replaced by periodic follow-up for nodules of borderline size (between 1.0 and $1.5 \mathrm{~cm}$ in maximum diameter) if they have sonographic features that are strongly associated with benign cytology.

A nodule of any size with sonographically suspicious features should also be considered for FNA. Sonographically suspicious features include:

- microcalcifications

- hypoechoic solid nodules

- irregular/lobulated margins

- intra-nodular vascularity

- nodal metastases (or signs of extracapsular spread)

This latter approach is controversial because it includes patients with microcarcinomas, in whom a survival benefit following an FNA diagnosis has not been documented. Nevertheless, the American Thyroid Association, ${ }^{1}$ the
Academy of Clinical Thyroidologists,${ }^{34}$ and a collaborative effort of the American Association of Clinical Endocrinologists and the Associazione Medici Endocrinologi ${ }^{47}$ make this recommendation (Table I). There are several reasons for this approach. A nodule that has suspicious sonographic features may not be malignant. If the nodule is benign by FNA, the patient can be reassured, and subsequent follow-up can be less frequent. On the other hand, if the FNA reveals that the nodule is malignant, surgery is generally recommended. The natural history of micropapillary carcinomas, however, is not well understood. Most remain indolent, as implied by the $13 \%$ prevalence of micropapillary cancers in the United States at autopsy examination. ${ }^{48} \mathrm{~A}$ minority follow a more aggressive course; this subgroup might be identified by sonographic evidence of lateral cervical node metastases, tumor multifocality, extrathyroidal invasion, or cytopathologic features that suggest a high-grade malignancy. ${ }^{49}$ The development and application of even more sensitive and specific markers of aggressive potential (including molecular and genetic markers) may one day facilitate triage of patients with a microcarcinoma.

There are few direct data on the cancer risk of thyroid incidentalomas detected by computed tomography (CT) or magnetic resonance imaging (MRI). They are seen in at least $16 \%$ of patients evaluated by neck CT or MRI. ${ }^{50}$ The risk of cancer in one study was predicted at $10 \%$, but it included only a limited number of patients who went on to FNA. ${ }^{51} \mathrm{CT}$ and MRI features can not determine the risk of malignancy, except in very advanced cases that are unlikely to be incidental. Until more data are available, incidentalomas seen on CT or MRI should undergo dedicated thyroid sonographic evaluation. Any nodule with sonographically suspicious features (see above) should be considered for FNA. In addition, lesions that have a maximum diame- 
ter greater than $1.0-1.5 \mathrm{~cm}$ should also be considered for FNA (see above).

As discussed in section "Indications for Performing an FNA of a Thyroid Nodule Discovered by Palpation," serum TSH levels may influence the decision to perform an FNA on an incidentaloma. Given the infrequency with which TSH levels are depressed, the decision to perform an FNA need not be delayed if the patient is undergoing sonography and the results are not available.

It may not be feasible or advisable to perform an FNA for all incidentalomas. There are too many, the costs and strain on the medical system would be too great, and such a practice would ultimately lead to needless surgery on many benign lesions. The goal in dealing with incidentalomas is to avoid FNA as best possible for nodules likely to be benign, while maximizing the number of malignant nodules that are diagnosed. The consensus in the literature and among professional societies specializing in thyroid diseases is that incidentalomas should undergo sonography and only those that have suspicious sonographic features, exceed a certain size $(1.0-1.5 \mathrm{~cm})$, or have clinical risk factors should undergo FNA. Given the imperfect ability of clinical factors to predict the risk of cancer, and the unavoidable overlap in sonographic features between benign and malignant nodules, any recommendation will result in some missed cancers and some FNAs of benign lesions.

Conclusions:

1. All focal ${ }^{18}$ FDG-PET-avid lesions should undergo FNA.

2. All hot nodules detected on sestamibi scans should undergo FNA.

3. Incidentalomas detected by US should undergo a dedicated thyroid sonographic evaluation.

4. Until more data are available, incidentalomas seen on CT or MRI should undergo a dedicated thyroid sonographic evaluation.

5. Any nodule with sonographically suspicious features should be considered for FNA.

6. Lesions with a maximum diameter greater than 1.0$1.5 \mathrm{~cm}$ should be considered for FNA.

\section{Indications for Performing a Thyroid FNA Using Palpation for Guidance}

Palpation-guided FNA can be performed with high levels of success in specific circumstances. ${ }^{2,52-54}$ In the setting of a new, palpable thyroid enlargement without a definable nodule on sonography, the decision to perform a biopsy or not still depends to a large degree on the sonographic appearance of the thyroid. If the thyroid is truly enlarged but is normal in echogenicity and echotexture, then malignancy is so unlikely that a biopsy is not necessary. On the other hand, if the enlarged thyroid is hypoechoic and heterogeneous/coarsened, then the differential includes lymphocytic thyroiditis (most commonly), and, rarely, uncommon malignancies like lymphoma and anaplastic cancer, as well as amyloid goiter. In such a case, an US-guided FNA may be warranted depending on the size of the thyroid, the degree of left to right asymmetry, other sonographic features, or based on clinical or laboratory findings.

The benefits of palpation-guided FNA of thyroid nodules are its reduced cost in comparison to US-guided FNA as well as its logistical efficiency: the practitioner can perform the procedure without an US machine or assistance from other practitioners. In the evaluation of individual patients with nodular disease, there are occasions when either palpation or US-guided FNA of a thyroid nodule are reasonable to perform. Published data from one study concluded that US evaluation changes the management in $63 \%$ of patients with palpable thyroid nodules. ${ }^{55}$ Thus, when thyroid nodules do not fulfill the criteria below, or when practitioners trained in palpation-guided aspiration are not readily available, US-guided FNA should be preferred.

\section{Conclusions:}

A palpation-guided FNA can be considered in the following scenarios:

1. A thyroid nodule $>1 \mathrm{~cm}$ in diameter has been confirmed via US examination of the thyroid. The sonographic examination is important because physical examination can be imprecise in determining nodule size and its origin from the thyroid rather than adjacent tissues. ${ }^{56}$

2. The thyroid nodule is discrete and readily identified on physical examination. Importantly, a diffuse or asymmetric goiter without a discrete nodule on physical examination should preclude palpationguided FNA in lieu of US-guided FNA.

3. The nodule is primarily solid $(<25 \%$ cystic) on US examination. ${ }^{57,58}$

4. The patient has no other head or neck illnesses or prior head or neck surgery that may affect the thyroid anatomy.

5. A prior nondiagnostic biopsy of the nodule has not occurred. In such cases, an US-guided FNA should be performed. ${ }^{59}$

6. Obtaining US guidance for FNA is logistically difficult or not readily available.

\section{Indications for Performing a Thyroid FNA Using Ultrasound for Guidance}

Ultrasound guidance for FNA of the thyroid gland is useful in the combined evaluation of the thyroid nodule, as it simultaneously allows detailed examination of the remainder of the thyroid gland, characterization of the nodule (solid, cystic, well-circumscribed, irregular, calcifications, vascularity, size, etc.), and accurate placement of the aspiration needle in the nodule of interest. The advantages 
of US guidance include a decreased rate of insufficient or inadequate cytology specimens in several studies in which these were compared. ${ }^{52,53,60-62}$ US also allows sampling from solid areas of partially cystic lesions, accounting for some increase in adequacy. ${ }^{63}$ Not all studies show a difference in adequacy and accuracy, or show a difference only for smaller lesions. ${ }^{60,64}$

US findings such as irregular margins, microcalcifications, intra-nodular vascularity, and the characteristics of other occult thyroid nodules can be used by the clinician to identify nodules at risk that should be sampled. ${ }^{45,65,66}$ US guidance can also provide additional information for patients who have had benign or nondiagnostic (i.e., insufficient cells/colloid) results from palpation-guided FNA. ${ }^{61,62}$ Re-evaluation of patients using US-guided FNA for those with initially benign or nondiagnostic results can lead to the reclassification of a substantial portion of patients and diagnose more cancers. ${ }^{61,62}$ Finally, there are US-specific findings that can be used to inform the results of the US-guided FNA (e.g., the benign sonographic appearance of a unilocular cyst explains why only cyst fluid was obtained by FNA).

Both palpation-localized and US-guided thyroid FNA are widely practiced. Several studies have shown, however, that US-guided FNA is a more sensitive technique than palpation-guided assessment. ${ }^{53,60,67}$ Regardless of the localization method utilized, high levels of operator training and experience are key determinants of successful FNA procedures. (See accompanying article in this issue by Ljung et al.)

Conclusions:

1. US guidance should be used to aspirate nodules that are not palpable.

2. US guidance should be used to aspirate nodules that have an appreciable $(>25 \%)$ cystic component.

3. US guidance should be used if a prior aspiration contained insufficient cells/colloid for interpretation.

4. US guidance for thyroid FNA may be used as an alternative to palpation localization because it permits the operator to:

(a) be certain that the nodule of interest is aspirated by direct imaging,

(b) be sure that a discrete nodule is present before aspiration, and

(c) avoid passing the needle into critical structures in the neck.

\section{The Informed Consent Form for Thyroid FNA}

Informed consent is the communication process between a patient and physician that results in the patient's agreement to undergo a particular procedure or treatment. ${ }^{68-74}$ For the purposes of the following discussion, the procedure is a thyroid FNA. ${ }^{75}$
The principle of informed consent is rooted in medical ethics, ${ }^{76}$ codified as a legal principle, ${ }^{77}$ and based on the assertion that a competent person has the right to determine what is done to her or him. ${ }^{68-74}$ In the informed consent process, the physician informs a patient about the risks and benefits of a proposed therapy or procedure and allows the patient to decide if the therapy or procedure should be undertaken. ${ }^{78}$ Informed consent in the research setting differs considerably from informed consent in a clinical context. ${ }^{79}$

In reality, all medical care, including the procuring of all laboratory tests, requires informal informed consent, except when the patient is incompetent to make a decision or gives up the right to provide it. ${ }^{68-74}$ Formal procedures of obtaining consent, such as the signing of a consent form, following the exchange of information and a patient-physician communication, are only undertaken in some circumstance, such as prior to major invasive procedures or surgery. ${ }^{68,80,81}$ Legislation regulating the conditions under which consent must be obtained vary greatly by state. ${ }^{68,72,73}$ Thus, providers (e.g., pathologists, radiologists, surgeons, endocrinologists, etc.) who perform FNA need to design informed consent policies and forms based on state regulations. In essence, there is a lack of standardization of national informed consent policy that determines exactly when and how informed consent is obtained.

National organizations like the American Medical Association (AMA) have provided general guidelines of informed consent. ${ }^{73}$ The AMA recommends that the following be disclosed and discussed with the patient:

1. The patient's diagnosis, if known;

2. The nature and purpose of a proposed treatment or procedure;

3. The risks and benefits of a proposed treatment or procedure;

4. Alternative options (regardless of their cost or the extent to which these options are covered by health insurance);

5. The risks and benefits of the alternative treatment or procedure;

6. The risks and benefits of not receiving or undergoing a treatment or procedure. ${ }^{73}$

The AMA Code of Medical Ethics establishes informed consent as an ethical obligation of physicians. ${ }^{73}$ Failure to obtain adequate informed consent renders a physician liable for negligence or battery and constitutes medical malpractice. ${ }^{68}$

Although it has been suggested that improved informed consent policies could result in improvements in the patient-physician relationship, patient compliance, patient trust of the healthcare system, and patient safety (by providing information that could reduce medical 
error), ${ }^{82}$ this hypothesis has not been definitively proved.

Many informed consent procedures are incomplete. ${ }^{6,69}$ In addition, less than $50 \%$ of the population understands commonly used medical terms, resulting in a "health literacy" problem that limits patients in their attempts to understand information. ${ }^{83-87}$ Several studies have focused on insufficiencies in procedures to obtain informed consent. Braddock et al. created a 3-tier evaluation procedure, in which the completeness of the informed consent discussions differed depending on the complexity of the decision. $^{70}$ Basic decisions (e.g., laboratory test ordering) require discussing the clinical nature of the decision and the evaluation of patient preferences. Intermediate decisions (e.g., medication changes) require a moderate depth of discussion and include adding a discussion of alternative treatments, including the risks and benefits of these alternatives and an assessment of patient understanding. Complex decisions (e.g., undergoing an operative procedure) require a discussion of the uncertainties associated with the procedure, in addition to the components listed previously.

Providing written information, which is also discussed during the informed consent process, may increase comprehension. ${ }^{88-91}$ This information, however, must be provided in a manner that is clearly understood by the patient. Hooper et al. found that patients with a high school education understand only $16 \%$ of all consent forms. ${ }^{92,93}$ Jubelirer et al. reported that, in a study of adult cancer patients, most had a reading level between 10 th and 11th grade. ${ }^{84}$ Jubelirer et al. recommended that consent forms be written at 3-grade levels below the highest level of education of the specific patient. ${ }^{84}$

For thyroid FNA, a consent form should be patient friendly and written so that the patient fully understands the procedure. Patient comprehension of thyroid FNA forms has not been rigorously studied. Potential complications should be listed on consent forms but written in a manner understandable to all patients. Concepts such as false-negative and false-positive proportions need to be discussed and written in terms that a patient understands; simply listing such numbers likely would not benefit most patients.

Currently, informed consent is receiving a great deal of attention, and a number of studies researching informed consent have been performed. The Agency for Healthcare Research and Quality (AHRQ) identified the challenge of addressing shortcomings such as missed, incomplete or not fully comprehended informed consent, as a significant patient safety opportunity. ${ }^{68,71,82}$ Thus, informed consent policies are evolving.

\section{Conclusions:}

1. Informed consent materials, including written documents, if used, should describe the FNA procedure and potential risks and complications.
2. The possibility of a hematoma, the most frequently occurring complication, should be mentioned.

3. Information should be presented in a manner to facilitate patient understanding.

4. It might be useful to mention the possibility of a noncontributory result.

5. Estimates of accuracy, such as false-negative or false-positive proportions, are not mandatory and should be considered only if the practitioner believes they would facilitate patient comprehension.

\section{Information Required on the Requisition Form that Accompanies a Thyroid FNA}

Federal regulations in the United States require that certain identifying information be provided to laboratories with all specimens submitted for laboratory testing. ${ }^{94}$ These include:

- name and address of person requesting the test

- patient's name or unique identifier

- patient's gender

- patient's age or date of birth

- name of the test to be performed

- specimen source

- date of specimen collection

- "any additional relevant information"

The purpose of this discussion is to consider what "additional relevant information" a laboratory needs to properly evaluate a thyroid FNA specimen.

With regard to the already required patient age, the risk of malignancy may be greater in individuals that are older (over age 60), and the risk is likely greater in younger individuals (children, generally under age 20). Risk is also increased in men. ${ }^{95-97}$ Papillary hyperplasias that occur in children can be confused with papillary thyroid cancer. $^{98}$

The location of the nodule (right vs. left; isthmus; upper pole, mid-pole, lower pole, etc.) should be specified on the requisition form to permit correlation with sonographic findings and subsequent histopathologic examination (if applicable). Such identification is necessary because patients often present with multiple nodules (some but not all of which may be biopsied), or they may develop other nodules over time.

There is, at best, an imperfect correlation between the size of a nodule and the likelihood of malignancy, but larger nodules $(>4 \mathrm{~cm})$ may be associated with a higher malignancy risk, and therefore size should be included. ${ }^{99}$

Benign cytologic changes that mimic malignancy, particularly papillary carcinoma, occur in some patients with autoimmune (Hashimoto's) thyroiditis. If not alerted to 
this history, a misdiagnosis can occur. ${ }^{100,101}$ Furthermore, nuclear alterations may be seen in patients with a history of I-131 therapy (for hyperthyroidism) or external radiation. ${ }^{102-104}$ In some patient with Graves' disease, an FNA of a nodule may include pleomorphic cells from the extra-nodular Graves' thyroid parenchyma that can be a pitfall in cytologic interpretation. ${ }^{105}$

It is important to note a personal history of malignancy because metastatic tumors to the thyroid can mimic the appearance of a primary thyroid neoplasm. Metastatic renal cell carcinoma mimics a follicular neoplasm; melanoma can mimic medullary carcinoma; metastatic lung cancer can mimic anaplastic carcinoma of the thyroid. Cytologists should be alerted to the possibility of a metastatic tumor in any patient with a history of malignancy.

Approximately $15 \%$ of medullary thyroid cancers are familial (familial MTC or MEN2a or 2b). Knowledge of family history can alert the pathologist to the possibility of medullary carcinoma. In addition, recent data show that papillary thyroid cancer can also be familial, ${ }^{106}$ and thus knowledge of such family history can alert the pathologist to consider papillary carcinoma.

The following information can be useful to the cytologist but is considered optional on the requisition form.

- Prior FNA. Morphologic alterations due to a prior FNA can affect cytologic interpretation. ${ }^{107}$

- Concurrent levothyroxine therapy. Levothyroxine (LT4) use can alter follicular cell morphology. Such altered morphology can be encountered in an FNA obtained because of nodule growth while a patient is taking LT4. Nodules that yield a more cellular benign specimen may demonstrate more colloid and degenerative changes after LT4 therapy. ${ }^{108}$

- TSH level. If a patient has Hashimoto's hypothyroidism or Graves' disease, cytologic findings can be affected. A lower serum TSH level is also associated with a lower risk of thyroid cancer. ${ }^{96}$

- Results of ultrasound examination

- US characteristics of the nodule

- US characteristics of surrounding extra-nodular thyroid parenchyma

- presence of other nodules

- location of nodule

US characteristics associated with malignancy include microcalcifications, hypoechogenicity, irregular margins, and increased vascularity. ${ }^{45}$ Predominantly cystic nodules may be less likely to be malignant. ${ }^{109} \mathrm{US}$ imaging of the surrounding extra-nodular thyroid may indicate that Hashimoto's (lymphocytic) thyroiditis is present, which, as noted above, can cause benign cytologic changes that mimic malignancy. Although the risk of cancer for an individual patient is the same whether he/she has a single or multiple nodules, the risk of malignancy per nodule is lower if multiple nodules are present. ${ }^{109}$ The lower parathyroid glands may be contiguous to the thyroid at its lower poles. Therefore, what is imaged as a lower pole hypoechoic thyroid nodule may be a parathyroid gland.

- Results of nuclear medicine imaging studies (functioning or not functioning). In general, a nodule that functions on an $\mathrm{I}^{123}$ scan should not undergo FNA. ${ }^{38,47,110}$

\section{Conclusions:}

At a minimum, the following data should appear on the requisition form that accompanies a thyroid FNA to the laboratory:

1. Usual required data for laboratory test submission (see above)

2. Location of the nodule

3. Size of the nodule

4. History of hypothyroidism, autoimmune thyroiditis, or a positive test for antithyroid antibodies

5. History of Graves' disease

6. History of $\mathrm{I}^{131}$ or external radiation therapy

7. Personal history of cancer

8. Family history of thyroid cancer

\section{References}

1. The American Thyroid Association Guidelines Task Force. Management guidelines for patients with thyroid nodules and differentiated thyroid cancer. Thyroid 2006;16:1-33.

2. Ravetto C, Columbo L, Dottorini ME. Usefulness of fine-needle aspiration in the diagnosis of thyroid carcinoma: A retrospective study in 37,895 patients. Cancer (Cancer Cytopathol) 2000;90: $357-363$.

3. Hegedus L. The thyroid nodule. N Engl J Med 2004;351:1764-1771.

4. Rojeski MT, Gharib JR. Nodular thyroid disease evaluation and management. N Engl J Med 1985;313:428.

5. Gharib H, Goellner JR. Evaluation of nodular thyroid disease. Endocrinol Metab Clin N Amer 1988;17:511-527.

6. Sherman SI, Angelos P, Ball D, et al. Thyroid carcinoma. J National Compr Canc Netw 2005;3:404-457.

7. Ross DS. Evaluation and nonsurgical management of the thyroid nodule. In: Randolph G, editor. Surgery of the Thyroid and Parathyroid Glands. Philadelphia: Saunders; 2003.

8. Wong CKM, Wheeler MH. Thyroid nodules: Rational management. World J Surg 2000;24:934-941.

9. Hegedus L, Bonnema SJ, Bennedbaek FN. Management of simple nodular goiter: Current status and future perspectives. Endocr Rev 2003;24:102-132.

10. Alexander EK, Hurwitz S, Heering JP, et al. Natural history of benign solid and cystic thyroid nodules. Ann Intern Med 2003; 138:315-318.

11. Burch HB. Evaluation and management of the thyroid nodule. Endocrinol Metab Clin N Amer 1995;24:663.

12. Ashcraft MW, Van Herle AJ. Management of thyroid nodules. II: Scanning techniques, thyroid suppressive therapy, and fine needle aspiration. Head Neck Surg 1981;3:297-322. 
13. Guidelines of the Papanicolaou Society of Cytopathology for fineneedle aspiration procedure and reporting. Mod Pathol 1997; 10:739-747.

14. Ogilvie JB, Piatigorsky EJ, Clark OH. Current status of fine needle aspiration for thyroid nodules. Adv in Surg 2006;40:223-238.

15. Wu M, Burstein DE. Fine needle aspiration. Cancer Invest 2004; 22:620-628.

16. Roh JL. Intrathyroid hemorrhage and acute upper airway obstruction after fine needle aspiration of the thyroid gland. Laryngoscope 2006;116:154-156.

17. Vu CK-F, Chang F, Doig L, Meenan J. A prospective control study of the safety and cellular yield of EUS-guided FNA or Trucut biopsy in patients taking aspirin, nonsteroidal anti-inflammatory drugs, or prophylactic low molecular weight heparin. Gastrointest Endosc 2006;63:808-813.

18. American Society of Gastrointestinal Endoscopy. Guideline on the management of anticoagulation and antiplatelet therapy for endoscopic procedures. Gastrointest Endosc 1998;48:672-675.

19. American Society for Gastrointestinal Endoscopy. ASGE guideline: The management of low-molecular-weight heparin and nonaspirin antiplatelet agents for endoscopic procedures. Gastrointest Endosc 2005;61:189-194.

20. Are C, Hsu JF, Schoder H, Shah JP, Larson SM, Shaha AR. FDGPET detected thyroid incidentalomas: Need for further investigation? Ann Surg Oncol 2007;14:239-247.

21. Chen YK, Ding HJ, Chen KT, et al. Prevalence and risk of cancer of focal thyroid incidentaloma identified by $18 \mathrm{~F}$-fluorodeoxyglucose positron emission tomography for cancer screening in healthy subjects. Anticancer Res 2005;25:1421-1426.

22. Choi JY, Lee KS, Kim HJ, et al. Focal thyroid lesions incidentally identified by integrated 18F-FDG PET/CT: Clinical significance and improved characterization. J Nucl Med 2006;47:609-615.

23. Chu QD, Connor MM, Lilien DL, Johnson LW, Turnage RH, Li BDL. Positron emission tomography (PET) positive thyroid incidentaloma: The risk of malignancy observed in a tertiary referral center. Am Surg 2006;72:272-275.

24. Cohen MS, Arslan N, Dehdashti F, et al. Risk of malignancy in thyroid incidentalomas identified by fluorodeoxyglucose-positron emission tomography. Surgery 2001;130:941-946.

25. Kang KW, Kim SK, Kang HS, et al. Prevalence and risk of cancer of focal thyroid incidentaloma identified by $18 \mathrm{~F}$-fluorodeoxyglucose positron emission tomography of metastasis evaluation and cancer screening in healthy subjects. J Clin Endocrinol Metab 2003;88:4100-4104.

26. Kim TY, Kim WB, Ryu JS, Gong G, Hong SJ, Shong YK. 18Ffluorodeoxyglucose uptake in thyroid from positron emission tomogram (PET) for evaluation in cancer patients: High prevalence of malignancy in thyroid PET incidentaloma. Laryngoscope 2005; 115:1074-1078.

27. Kresnik E, Gallowitsch HJ, Mikosch P, et al. Fluorine-18-fluorodeoxyglucose positron emission tomography in the preoperative assessment of thyroid nodules in an endemic goiter area. Surgery 2003;133:294-299.

28. Yi JG, Marom EM, Munden RF, et al. Focal uptake of fluorodeoxyglucose by the thyroid in patients undergoing initial disease staging with combined PET/CT for non-small cell lung cancer. Radiology 2005;236:271-275.

29. Alonso O, Lago G, Mut F, et al. Thyroid imaging with Tc-99m MIBI in patients with solitary cold single nodules on pertechnetate imaging. Clin Nucl Med 1996;21:363-367.

30. Hurtado-Lopez LM, Arellano-Montano S, Torres-Acosta EM, et al. Combined of fine-needle aspiration biopsy. MIBI scans and frozen section biopsy offers and the best diagnostic accuracy in the assessment of the hypofunctioning solitary thyroid nodule. Eur J Nucl Med Mol Imaging 2004;31:1273-1279.

31. Kresnik E, Gallowitsch HJ, Mikosch P, Gomez I, Lind P. Technetium-99M-MIBI scintigraphy of thyroid nodules in an endemic goiter area. J Nucl Med 1997;38:62-65.
32. Mezosi E, Bajnok L, Gyory F, et al. The role of technetium-99m methoxyisobutylisonitrile scintigraphy in the differential diagnosis of cold thyroid nodules. Eur J Nucl Med 1999;26:798-803.

33. Sathekge MM, Mageza RB, Muthuphei MN, Modiba CM, Clauss RC. Evaluation of thyroid nodules with technetium-909m MIBI and technetium-99m pertechnetate. Head Neck 2001;23:305-310.

34. Academy of Clinical Thyroidologists (http://www.thyroidologists. com/papers.html). Position Paper on FNA for Non-Palpable Thyroid Nodules (08/ 2006).

35. Brander AEE, Viikinkoski VP, Nickels JI, Kivisaari LM. Importance of thyroid abnormalities detected in US screening: A 5-year follow-up. Radiology 2000;215:801-806.

36. Cooper DS, Doherty GM, Haugen BR, et al. Management guidelines for patients with thyroid nodules and differentiated thyroid cancer. Thyroid 2006;16:109-140.

37. Chung WY, Chang HS, Kim EK, Park CS. Ultrasonographic mass screening for thyroid carcinoma: A study in women scheduled to undergo a breast examination. Surg Today 2001;31:763-767.

38. Frates MC, Benson CB, Charboneau JW, et al. Management of thyroid nodules detected at US: Society of Radiologists in Ultrasound Consensus Conference Statement. Radiology 2005;237:794-800.

39. Kang HW, No JH, Chung JH, et al. Prevalence, clinical and ultrasonographic characteristics of thyroid incidentalomas. Thyroid 2004; 14:29-33.

40. Kim EK, Park CS, Chung WY, Oh KK, Kim DI, Lee JT, Yoo HS. New sonographic criteria for recommending fine-needle aspiration biopsy of nonpalpable solid nodules of the thyroid. AJR Am J Roentgenol 2002;178:687-691.

41. Leenhardt L, Hejblum G, Franc B, et al. Indications and limits of ultrasound-guided cytology in the management of nonpalpable thyroid nodules. J Clin Endocrinol Metab 1999;84:24-28.

42. Liebeskind A, Sikora AG, Komisar A, Slavit D, Fried K. Rates of malignancy in incidentally discovered thyroid nodules evaluated with sonography and fine-needle aspiration. J Ultrasound Med 2005; 24:629-634.

43. Nabriski D, Ness-Abramof R, Brosh T, Konen O, Shapiro MS, Shenkman L. Clinical relevance of non-palpable thyroid nodules as assessed by ultrasound-guided fine needle aspiration biopsy. J Endocrinol Invest 2003;26:61-64.

44. Nan-Goong IS, Kim HY, Gong G, et al. Ultrasonography-guided fine-needle aspiration of thyroid incidentaloma: Correlation with pathological findings. Clin Endocrinol 2004;60:21-28.

45. Papini E, Guglielmi R, Bianchini A, et al. Risk of malignancy in nonpalpable thyroid nodules: Predictive value of ultrasound and color-Doppler features. J Clin Endocrinol Metab 2002;87:19411946.

46. Steele SR, Martin MJ, Mullenix PS, Azarow KS, Andersen CA. The significance of incidental thyroid abnormalities identified during carotid duplex ultrasonography. Arch Surg 2005;140:981-985.

47. AACE/AME Task Force on Thyroid Nodules. American Association of Clinical Endocrinologists and Associazione Medici Endocrinologi: Medical guidelines for clinical practice for the diagnosis and management of thyroid nodules. Endocrine Pract 2006;12:63101.

48. Harach HR, Franssila KO, Wasenius VM. Occult papillary carcinoma of the thyroid. A "normal" finding in Finland. A systematic autopsy study. Cancer 1985;56:531-538.

49. Ito Y, Miyauchi A. A therapeutic strategy for incidentally detected papillary microcarcinoma of the thyroid. Nat Clin Pract Endocrinol Metab 2007;3:240-248.

50. Yousem DM, Huang T, Loevner LA, Langlotz CP. Clinical and economic impact of incidental thyroid lesions found with CT and MR. AJNR Am J Neuroradiol 1997;18:1423-1428.

51. Shetty SK, Maher MM, Hahn PF, Halpern EF, Aquino SL. Significance of incidental thyroid lesions detected on CT: Correlation among CT, sonography, and pathology. AJR Am J Roentgenol 2006;187:1349-1356. 
52. Carmeci C, Jeffrey RB, McDougall IR, Nowels KW, Weigel RJ. Ultrasound-guided fine-needle aspiration biopsy of thyroid masses. Thyroid 1998;8:283-289.

53. Danese D, Sciacchitano S, Farsetti A, Andreoli M, Pontecorvi A. Diagnostic accuracy of conventional versus sonography-guided fine-needle aspiration biopsy of thyroid nodules. Thyroid 1998;8: $15-21$.

54. Ko HM, Jhu IK, Yang SH, et al. Clinicopathologic analysis of fine needle aspiration cytology of the thyroid. A review of 1,613 cases and histopathologic diagnosis. Acta Cytol 2003;47:727-332.

55. Marqusee E, Benson CB, Frates MC, Doubilet PM, Larsen PR, Cibas ES, Mandel SJ. Utility of ultrasound in the management of nodular thyroid disease. Ann Intern Med 2000;133:696-700.

56. Brander A, Viikinkoski P, Tuuhea J, Voutilainen L, Kivisaari L. Clinical versus Ultrasound examination of the thyroid gland in common clinical practice. J Clin Ultrasound 1992;20:37-42.

57. Alexander EK, Heering JP, Benson CB, Frates MC, Doubilet PM, Cibas ES, Marqusee E. Assessment of nondiagnostic ultrasoundguided fine needle aspiration of thyroid nodules. J Clin Endocrinol Metab 2002;87:4924-4927.

58. Hall TL, Layfield LJ, Philippe A, Rosenthal D. Sources of diagnostic error in fine needle aspiration of the thyroid. Cancer 1989; 63:718-725.

59. Braga M, Cavalcanti TC, Collaco LM, Graf H. Efficacy of ultrasound-guided fine-needle aspiration biopsy in the diagnostis of complex thyroid nodules. J Clin Endocrinol Metab 2001;86:40894091.

60. Cesur M, Corapcioglu D, Bulut S, et al. Comparison of palpationguided fine-needle aspiration biopsy to ultrasound-guided fine-needle aspiration biopsy in the evaluation of thyroid nodules. Thyroid 2006;16:555-561.

61. Yokozawa T, Fukata S, Kuma K, et al. Thyroid cancer detected by ultrasound-guided fine-needle aspiration biopsy. World J Surg 1996;20:848-853.

62. Yokozawa T, Miyauchi A, Kuma K, et al. Accurate and simple method of diagnosing thyroid nodules the modified technique of ultrasound-guided fine needle aspiration biopsy. Thyroid 1995;5: $141-145$.

63. Court-Payen M, Nygaard B, Horn T, et al. US-guided fine-needle aspiration biopsy of thyroid nodules. Acta Radiol 2002;43:131140.

64. Accurso A, Rocco N, Palumbo A, et al. Usefulness of ultrasoundguided fine-needle aspiration cytology in the diagnosis of non-palpable small thyroid nodules. Tumori 2005;91:355-357.

65. Koike E, Yamashita H, Noguchi S, et al. Effect of combining ultrasonography and ultrasound-guided fine-needle aspiration biopsy findings for the diagnosis of thyroid nodules. Eur J Surg 2001;167:656-661.

66. Deandrea M, Mormile A, Veglio M, et al. Fine-needle aspiration biopsy of the thyroid: Comparison between thyroid palpation and ultrasonography. Endocr Prac 2002;8:282-286.

67. Hatada T, Okada K, Ishii H, et al. Evaluation of ultrasound-guided fine-needle aspiration biopsy for thyroid nodules. Am J Surg 1998;175:133-136.

68. Shojania K, Duncan B, McDonald K, Wachter RM, editors. Making Health Care Safer: A Critical Analysis of Patient Safety Practices. Evidence Report/Technology Assessment No. 43; AHRQ publication 01-E058. Rockville, MD: Agency for Healthcare Research and Quality; 2001.

69. Pizzi LT, Goldfarb NI, Nash DB. Chapter 48: Procedures for obtaining informed consent. Available at http://www.ahrq.gov/ clinic/ptsafety/chap48.htm. Accessed 25 February, 2007.

70. Braddock CH III, Edwards KA, Hasenberg NM, Laidley TL, Levinson W. Informed decision making in outpatient practice: Time to get back to basics. JAMA 1999;282:2313-2320.

71. Pizzi LT, Goldfarb NI, Nash DB. Procedures for Obtaining Informed Consent. In: Shojania K, Duncan B, McDonald K, Wachter RM, editors. Making health care safer: A critical analysis of patient safety practices. Volume AHRQ publication 01-E058. Rockville, MD: Agency for Healthcare Research and Quality; 2001. p 546-554.

72. iMedConsent. The standard of care for informed consent. Available at: http://www.dialogmedical.com/ic.htm. Accessed 25 February, 2007.

73. Informed Consent: American Medical Association. Available at http://www.ama-assn.org/ama/pub/category/4608.html. Accessed 25 February, 2007.)

74. Berg JW, Appelbaum PS, Parker LS, Lidz CW. Informed consent: Legal theory and clinical practice. Oxford: Oxford University Press; 2001.

75. The Papanicolaou Society of Cytopathology Task Force on Standards of Practice. Guidelines of the Papanicolaou Society of Cytopathology for fine-needle aspiration procedure and reporting. Diagn Cytopathol 1997;17:239-247.

76. Reich WT. Informed consent. Encyclopedia of bioethics. New York: Simon \& Schuster; 1995.

77. Levinson W, Roter DL, Mullooly JP, Dull VT, Frankel RM. Physician-patient communication. The relationship with malpractice claims among primary care physicians and surgeons. JAMA 1997;277:553-559.

78. Leape LL, Berwick DM, Bates DW. What practices will most improve patient safety? Evidence-based medicine meets patient safety. JAMA 2002;288:501-507.

79. Edwards SJ, Lilford RJ, Thornton J, Hewison J. Informed consent for clinical trials: In search of the "best" method. Soc Sci Med 1998;47:1825-1840.

80. Lavelle-Jones C, Byrne DJ, Rice P, Cuschieri A. Factors affecting quality of informed consent. BMJ 1993;306:885-890.

81. Lidz CW, Appelbaum PS, Meisel A. Two models of implementing informed consent. Arch Intern Med 1988;48:1385-1389.

82. Kohn KT, Corrigan JM, Donaldson MS, editors. To err is human: Building a safer health system. Washington, DC: Committee on Quality Health Care in America, Institute of Medicine, National Academy Press; 1999.

83. Hopper KD, TenHave TR, Hartzel J. Informed consent forms for clinical and research imaging procedures: How much do patients understand? AJR Am J Roentgenol 1995;164:493-496.

84. Jubelirer SJ, Linton JC, Magnetti SM. Reading versus comprehension: Implications for patient education and consent in an outpatient oncology clinic. J Cancer Educ 1994;9:26-29.

85. Boyle CM. Difference between patients' and doctors' interpretation of some common medical terms. BMJ 1970;1:286-289.

86. Dawes PJ, O'Keefe L, Adcock S. Informed consent: The assessment of two structured interview approaches compared to the current approach. J Laryngol Otol 1992;106:420-424.

87. Whitney SN, McGuire AL, McCullough LB. A typology of shared decision making, informed consent, and simple consent. Ann Intern Med 2004;140:54-59.

88. Bottrell MM, Alpert H, Fischbach RL, Emanuel LL. Hospital informed consent procedure forms: Facilitating quality patientphysician interaction. Arch Surg 2000;135:26-33.

89. Greenfield S, Kaplan S, Ware JE, Jr. Expanding patient involvement in care: Effects on patient outcomes. Ann Intern Med 1985; 102:520-528.

90. VHA Informed Consent for Clinical Treatments and Procedures. VHA Handbook. Washington DC: Department of Veterans Affairs. Veterans Health Administration 1004(1) January 29; 2003.

91. Stewart MA. Effective physician-patient communication and health outcomes: A review. CMAJ 1995;152:1423-1433.

92. Hopper KD, TenHave TR, Tully DA, Hall TE. The readability of currently used surgical/procedure consent forms in the United States. Surgery 1998;123:496-503.

93. Hopper KD, Lambe HA, Shirk SJ. Readability of informed consent forms for use with iodinated contrast media. Radiology 1993;87: 279-283. 


\section{INDICATIONS FOR THYROID FNA AND PRE-FNA REQUIREMENTS}

94. Centers for Medicare and Medicaid Services. Available at http:// wwwn.cdc.gov/clia/pdf/42cfr493_2003.pdf. Volume 2007: Federal Register. p Laboratory Requirements.

95. Belfiore A, LaRosa GL, La PGA, Giuffrida D, Milazzo G, Lupo L, Regalbuto C, Vigneri R. Cancer risk in patients with cold thyroid nodules: Relevance of iodine intake, sex, age, and multinodularity. Am J Med 1992;93:363-369.

96. Boelaert K, Horacek J, Holder RL, Watkinson JC, Sheppard MC, Franklyn JA. Serum thyrotropin as a novel predictor of malignancy in thyroid nodules investigated by fine-needle aspiration. J Clin Endocrinol Metab 2006;91:4295-4301.

97. Hung W. Solitary thyroid nodules in 93 children and adolescents. Horm Res 1999;52:15-18.

98. Khurana KK, Baloch ZW, LiVolsi VA. Aspiration cytology of pediatric solitary papillary hyperplastic thyroid nodule: Potential pitfall. Arch Pathol Lab Med 2001;125:1575-1578.

99. Hamming JF, Goslings BM, van Steenis GJ, van Ravenswaay CH, Hermans J, van de Velde CJH. The value of fine-needle aspiration biopsy in patients with nodular thyroid disease divided into groups of suspicion of malignant neoplasms on clinical grounds. Arch Intern Med 1990;150:113-116.

100. Kollur SM, Sayed SE, El Hag A. Follicular thyroid lesions coexisting with Hashimoto's thyroiditis: Incidence and possible sources of diagnostic errors. Diagn Cytopathol 2003;28:35-38.

101. Nguyen GK, Ginsberg J, Crockford PM, Villanueva RR. Hashimoto's thyroiditis: Cytodiagnostic accuracy and pitfalls. Diagn Cytopathol 1997; 16:531-536.
102. Pretorius HT, Katikineni M, Kinsella TJ, Barsky SH, Brennan JF, Chu EW, Robbin J. Thyroid nodules after high-dose external radiotherapy: Fine-needle aspiration cytology in diagnosis and management. JAMA 1982;247:3217-3220.

103. Centeno BA, Szyfelbein WM, Daniels GH, Vickery AL. Fine needle aspiration biopsy of the thyroid gland in patients with prior Graves' disease treated with radioactive iodine. Acta Cytol 1996; 40:1189-1197.

104. Granter SR, Cibas ES. Cytologic findings in thyroid nodules after 131I treatment of hyperthyroidism. Am J Clin Pathol 1997;107: $20-25$.

105. Jayaram G, Singh B, Marwaha RK. Graves' disease: Appearance in cytologic smears from fine needle aspirates of the thyroid gland. Acta Cytol 1989;33:36-40.

106. Hemminki K, Eng C, Chen B. Familial risks for non-medullary thyroid cancer. J Clin Endocrinol Metab 2005;90:5747-5753.

107. Baloch ZW, LiVolsi VA. Post fine-needle aspiration histologic alterations of thyroid revisited. Am J Clin Pathol 1998;112:311-316.

108. Vermiglio F, Lo Presti VP, Violi MA, et al. Changes in both size and cytological feature of thyroid nodule after levothyroxine treatment. Clin Endocrinol 2003;59:347-353.

109. Frates MC, Benson CB, Doubilet PM, et al. Prevalence and distribution of carcinoma in patients with solitary and multiple thyroid nodules on sonography. J Clin Endocrinol Metab 2006;91:3411-3417.

110. Cooper DS, Doherty GM, Haugen BR, et al. Management guidelines for patients with thyroid nodules and differentiated thyroid cancer. Thyroid 2006;16:1-32. 